\title{
Change of the Pure Tone Threshold as a Function of Frequency and Clinical Characteristics in Definite Meniere's Disease
}

\author{
Ki-Yong Choi*, Hong Geun Kim*, Kun Woo Kim, Min Young Lee, and Jae Yun Jung \\ Department of Otorhinolaryngology-Head and Neck Surgery, Dankook University College of Medicine, Cheonan, Korea
}

\section{명확한 메니에르병 환자에서 주파수별 순음역치 변동성과 임상 증상과의 관계}

최기용* · 김홍근* · 김건우 · 이민영 · 정재윤

단국대학교 의과대학 이비인후-두경부외과학교실

\author{
Received April 24, 2018 \\ Revised July 31,2018 \\ Accepted August 6, 2018 \\ Address for correspondence \\ Jae Yun Jung, MD, PhD \\ Department of Otorhinolaryngology- \\ Head and Neck Surgery, \\ Dankook University \\ College of Medicine, \\ 201 Manghyang-ro, Dongnam-gu, \\ Cheonan 31116, Korea \\ Tel $+82-41-550-3973$ \\ Fax $+82-41-556-1090$ \\ E-mail jjkingy2k@gmail.com \\ *These authors contributed equally \\ to this work.
}

Background and Objectives One of the characteristics of Meniere's disease is pure tone threshold shift at low frequencies in the lesion; although, in some patients, more pure tone threshold shifts were also shown at mid or high frequencies. Authors speculated that the most varied pure tone frequency may be related with diversity of clinical symptoms and other characteristics.

Subjects and Method We reviewed medical records of 85 patients who met the criteria of definite Meniere's disease (1995 American Academy of Otolaryngology-Head and Neck Surgery). Patients were classified into 3 groups (high frequency, mid frequency, low frequency) depending on the frequency at which pure tone threshold changes encountered the most. The vestibular function tests and clinical characteristics were compared between the groups.

Results Thirty-six patients $(42.0 \%)$ showed pure tone threshold changes at 0.25 or $0.5 \mathrm{kHz}$ (low frequency group). Twenty-five patients $(30.0 \%)$ showed greatest pure tone threshold change at 1 or $2 \mathrm{kHz}$ (mid frequency group). Twenty-four patients $(28.0 \%)$ belonged to the high frequency group with most changes taking place not lower than $4 \mathrm{kHz}$. Frequency of vertigo attack, and duration of vertigo attack did not differ between the groups. Low frequency group showed more chance of tinnitus with statistical significance. Vestibular evoked myogenic potentials (VEMP) abnormality was more frequently encountered in the low frequency group.

Conclusion This study shows that changes in the pure tone threshold is not confined to low frequencies in definite Meniere's disease. Patients with pure tone threshold changes at low frequencies have more chance of tinnitus and abnormal cVEMP.

Korean J Otorhinolaryngol-Head Neck Surg 2019;62(2):89-94

Key Words Definite Meniere's disease · Frequency · Pure tone audiometry.

\section{서 론}

메니에르병은 반복적으로 발생하는 어지럼증과 청력 장 애, 이명, 이충만감을 주 증상으로 하는 질환으로 메니에르

This is an Open Access article distributed under the terms of the Creative Commons Attribution Non-Commercial License (https://creativecommons.org/licenses/by-nc/4.0) which permits unrestricted non-commercial use, distribution, and reproduction in any medium, provided the original work is properly cited.
병 환자가 호소하는 초기 증상은 어지럼증, 이명, 청력장애가 있다.1) 메니에르병 초기에 이 세 가지 증상이 같이 나타나기 도 한다.

메니에르병에서 보이는 청력 장애는 주로 저주파수 영역의 감각신경성 난청이 주를 이루고 있다고 알려져 있다. ${ }^{2)}$ 메니에 르병 초기의 청력검사는 주로 위로 경사진 형태(27\%) 또는 편 평한 형태(55\%)를 보이는 반면 후기의 청력검사는 아래로 경 
사진 형태를 보이고 있다고 알려져 있다. ${ }^{3)}$

하지만 메니에르병 환자에서의 청력 저하는 다양한 형태 를 보이며 시간이 지나면서 불규칙한 변화를 보인다. 특히, 어 지럼증이 악화될 경우에는 청력이 감소하고 어지럼증이 완화 될 경우에는 청력이 회복되는 경우도 있다. 메니에르병이 발생 한지 5 10년 후에는 청력의 역치 값이 50 60 dB로 고착되기 도 한다.

임상적으로 메니에르병 환자들의 청력이 변동하는 것을 관 찰할 수 있지만 이 변동이 어떠한 의미를 내포하는지 아직 설 명되지 않고 있다. 그리고 메니에르병 환자들의 청력 변동 및 청력도 분석 역시 일치하지 않는다. ${ }^{5,6)}$ 하지만 최근 청력 변동 의 정도가 환자의 예후와 연관이 있을 가능성을 시사했고, 또한 와우의 주파수 위치와 전정기관과의 해부학적 관계를 생각해 보면 청력 변화량이 큰 주파수가 어디냐에 따라 전정 기능 검사 결과 및 임상 특징의 차이가 발생할 수 있다.

그리하여 본 연구에서는 메니에르병 환자들을 가장 변동 이 큰 주파수에 따라서 분류하고 그 분류에 따른 임상 증상 과 전정기능검사의 양상을 비교 분석하였다.

\section{대상 및 방법}

2005년 1월부터 2013년 12월까지 명확한 메니에르병(1995년 American Academy of Otolaryngology-Head and Neck Surgery의 기준)으로 진단받은 환자 중에서 순음청력검사를 1 년 이내에 3 회 이상 시행하고 1년 이상 정기적으로 외래 경과 관찰을 시행한 85 명(여자 58명, 남자 27명)을 대상으로 하였다. ${ }^{8)}$ 본 연구는 '헬싱키 선언(Declaration of Helsinki)'을 준수 하 였으며, 단국대학교병원 연구윤리심의위원회의 승인을 받고 진 행되었다(IRB No. 2018-10-010).

메니에르병 환자의 환측 부위, 두통 동반 여부, 이명 및 이 충만감 동반 여부, 어지럼증의 지속시간과 발생빈도 등의 증 상을 환자의 의무기록을 바탕으로 치료가 시작되기 전 초기 평가시의 임상 양상을 적용하여 분석하였다. 순음청력 검사 는 GSI 10(Welch Allyn, West Midlands, UK), Aurical Plus (GNOtometrics, Taastrup, Denmark)을 사용하여 시행하였 으며 $250,500,1000,2000,3000,4000,8000 \mathrm{~Hz}$ 주파수 영 역을 검사하였다. 주파수의 변동은 메니에르병 진단 후 3번 의 연속된 청력 검사를 기준으로 하였고, 순음청력검사에서 메니에르병에 이환된 쪽 귀의 6개 주파수 별 순음청력역치 변화 정도를 확인하였다. 청력의 변화 정도는 $5 \mathrm{~dB}$ 이상을 모 두 포함하였으며 호전 악화 유무 상관없이 그 절대적인 변화 량을 측정하였다. 이때 변화량이 같은 경우에는 청력이 보다 안 좋은 쪽으로 선별하였다. 이때 순음청력역치 변동이 큰 주파
수에 따라서 저주파수(그룹 A: $250,500 \mathrm{~Hz}$ )에서 변동이 큰 그룹, 중주파수(그룹 B: 1000, $2000 \mathrm{~Hz}$ )에서 변동이 큰 그룹, 그리고 고주파수(그룹 C: 4000, $8000 \mathrm{~Hz}$ )에서 변동이 큰 그 룹으로 나누었다. 또한 청력의 변화가 호전/악화인지 구분하 여 각 그룹별로 확인하였다.

전체 환자 중 79 명이 진단 시 1회 전기와우청력검사(electrocochleography)를 시행하였고, 63명이 단일온도안진검사 (monothermal caloric test, $17^{\circ} \mathrm{C}$ )를 시행하였으며, 80 명이 Nicolet Biomedical Viking IV(VIASYS Healthcare Inc., Conshohocken, PA, USA)를 이용하여 전정유발근전위검사 를 시행하였다.

전기와우청력검사는 외이도에 금(gold) 전극을 위치시키 고 $90 \mathrm{~dB}$ 의 자극음을 $100 \mathrm{msec}$ 동안 반복하여 자극하는 alternating polarity click 방법으로 1000회의 자극을 가하 였다. Summating potential/action potential비의 비정상 기 준은 0.4 이상으로 정하였다.

전정유발근전위 측정을 위해 활성 전극은 흥쇄유돌근 중간 부위에, 접지전극은 이마 중부에 붙이고, 기준전극은 흥쇄유 돌근의 쇄골 접합 부위에 부착하였으며 검사는 방음실에서 실시하였다. 검사 시 고개를 검사 측의 반대편으로 돌린 후 피 검자가 일정한 힘을 유지하도록 하였다. 소리 자극은 귀속 삽 입용 수신기를 이용하여 $500 \mathrm{~Hz}$ 의 tone burst 음을 $100 \mathrm{~dB}$ $\mathrm{nHL}$ 강도로 주었으며, 음의 상승/하강시간은 $2 \mathrm{msec}$, plateau time은 $3 \mathrm{msec}$ 였으며, 각 조건에서 160회 반복하여 측정되었 다. 전정유발근전위의 비정상은 파형이 나오지 않거나 interaural amplitude difference(IAD)가 $40 \%$ 이상인 경우로 정하 였다.

통계학적인 검정은 SPSS ver. 13.0(SPSS Inc., Chicago, IL, USA) 혹은 GraphPad Prism(GraphPad Software, La Jolla, $\mathrm{CA}, \mathrm{USA})$ 을 이용하였다. 모든 연속변수의 경우 정규 분포 의 여부를 Kolmogorov-Smirnov 검정으로 확인 후 그 결과 에 따라 통계 방법을 다시 설정해서 진행하였고, 정규분포를 하는 경우 independent t-test를, 정규 분포를 하지 않는 경우 Mann-Whitney test를 사용하였다. 세군 이상의 통계를 돌리 는 경우 one-way analysis of variance(ANOVA) 혹은 Krus$\mathrm{kal}-\mathrm{Wallis}$ 검정을 이용한 후 사후 검정을 추가하였다. 빈도 비교의 경우에는 chi-square test 혹은 Fisher's exact test를 사용하였다.

\section{결 과}

저주파수 $(0.25,0.5 \mathrm{kHz})$ 에서 가장 큰 변동을 보이는 환자 는 36명이었고(42.0\%, 그룹 A), 중간주파수 $(1,2 \mathrm{kHz})$ 에서 
Table 1. Changes in hearing thresholds of different frequency ranges in each group

\begin{tabular}{cccc}
\hline $\mathrm{dB} \mathrm{HL}$ & Low frequency & Mid frequency & High frequency \\
\hline Group A & $30.7 \pm 13.5$ & $20.6 \pm 13.2$ & $15.1 \pm 9.6$ \\
Group B & $23.0 \pm 15.4$ & $35.2 \pm 18.2$ & $20.6 \pm 16.3$ \\
Group C & $16.3 \pm 10.6$ & $22.3 \pm 15.0$ & $32.7 \pm 16.6$ \\
\hline
\end{tabular}

Table 2. Number of patients with threshold changes in each group

\begin{tabular}{lcccc}
\hline & $I m p \rightarrow I m p$ & $I m p \rightarrow$ Agg & Agg $\rightarrow I m p$ & Agg $\rightarrow$ Agg \\
\hline Group A & 14 & 9 & 10 & 3 \\
Group B & 5 & 6 & 9 & 5 \\
Group C & 4 & 4 & 11 & 5
\end{tabular}

Imp: improved, Agg: aggravated

가장 큰 변동을 보이는 환자는 25명이었다( $30.0 \%$, 그룹 B). 고주파수 $(4,8 \mathrm{kHz})$ 에서 가장 큰 변동을 보이는 환자는 24명 이었다 $(28.0 \%$, 그룹 C). 각 그룹별 평균 청력의 변동은 각각 $30( \pm 14) \mathrm{dB}, 35( \pm 19) \mathrm{dB}, 33( \pm 16) \mathrm{dB}$ 이었다. 각 군별 청력 변동이 평균을 분석하였을 때, 그룹 $\mathrm{A}$ 는 저주파수, 그룹 $\mathrm{B}$ 는 중주파수, 그룹 $\mathrm{C}$ 는 고주파수 영역에서 가장 큰 변동이 관찰 되었고, 가장 변동의 큰 주파수 영역 외에 다른 영역의 15 23 dB의 변동도 확인되었다(Table 1). 각 군에서 청력의 주파수 영역별 청력의 변동을 비교하였을 때, 모든 그룹에서 주파수 영역별 청력의 변동 차이가 있었고(그룹 $\mathrm{A}:$ KruskalWallis test, KW statistics=24.63, $p<0.0001$; 그룹 $\mathrm{B}$ : KruskalWallis test, $\mathrm{KW}$ statistics $=10.94, p=0.0042$; 그룹 C KruskalWallis test, $\mathrm{KW}$ statistics $=12.84, p=0.0016)$, 사후 검정에서 그룹 $\mathrm{A}$ 의 경우 저음 영역의 변동이 다른 주파수 영역에 비해 통계적으로 유의하게 증가되어 있었고(Dunn's Multiple Comparison Test; 저음 vs. 중음: $p<0.01$, 저음 vs. 고음: $p<0.001$, 그룹 $\mathrm{B}$ 의 경우 중음 영역의 변동이 다른 주파수 영역에 비해 통계적으로 유의하게 증가되어 있었고(Dunn's Multiple Comparison Test; 저음 vs. 중음: $p<0.05$, 중음 vs. 고음: $p<0.01$ ) 그리고 그룹 $\mathrm{C}$ 의 경우 고음 영역의 변동이 저음 영역에 비해 통 계적으로 유의하게 증가되어 있었다(Dunn's Multiple Comparison Test; 저음 vs. 고음: $p<0.01$. 청력의 양상은 Table 2 와 같으며 그룹 $\mathrm{A}$ 의 경우 호전을 반복하는 경우가 가장 흔했 고, 그룹 B와 C의 경우에는 악화되었다 호전되는 경우가 가 장 많았으나 통계적인 유의성은 없었다(Fisher's exact test: $p=0.313)$.

세 그룹 모두 회전성의 어지럼증 양상을 보이고 있었으며 환자들에게 한 달에 몇 번 정도 어지럼증이 발생하는지 확인 하였고 그룹 $\mathrm{A}$ 는 7.4회, 그룹 $\mathrm{B}$ 는 4.1회, 그룹 $\mathrm{C}$ 는 8.7회로 그 룹 $\mathrm{A}$ 와 그룹 $\mathrm{C}$ 의 경우 어지럼증의 발생빈도가 그룹 $\mathrm{B}$ 에 비 해 높았으나 이것은 통계적으로 유의하지 않았다(KruskalWallis test, KW statistics $=0.8456, p=0.6552$ )(Fig. 1).

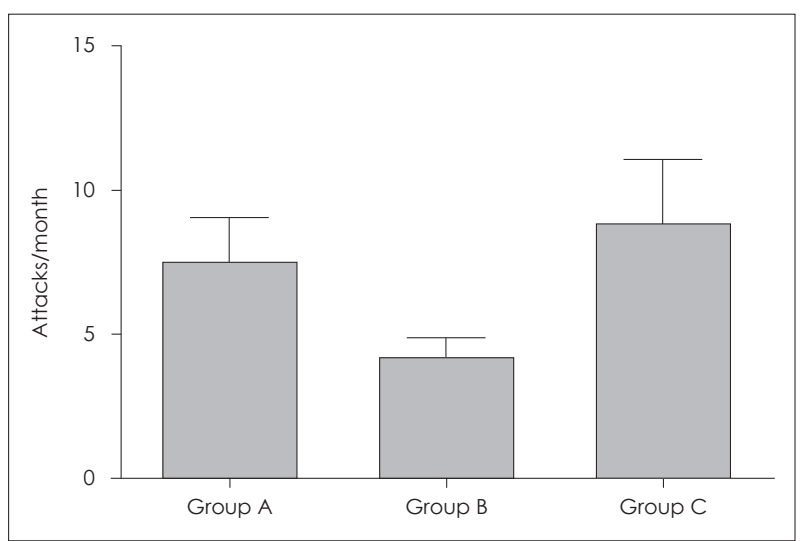

Fig. 1. Frequency of dizziness attacks in each group. There was no statistical difference among groups. Error bars indicate standard error $(p>0.05)$. Group A: low frequency fluctuation group $(0.25,0.5 \mathrm{kHz})$, Group B: mid frequency flucutaion group (1, 2 $\mathrm{kHz})$, and Group C: high frequency flucutaion group $(4,8 \mathrm{kHz})$.

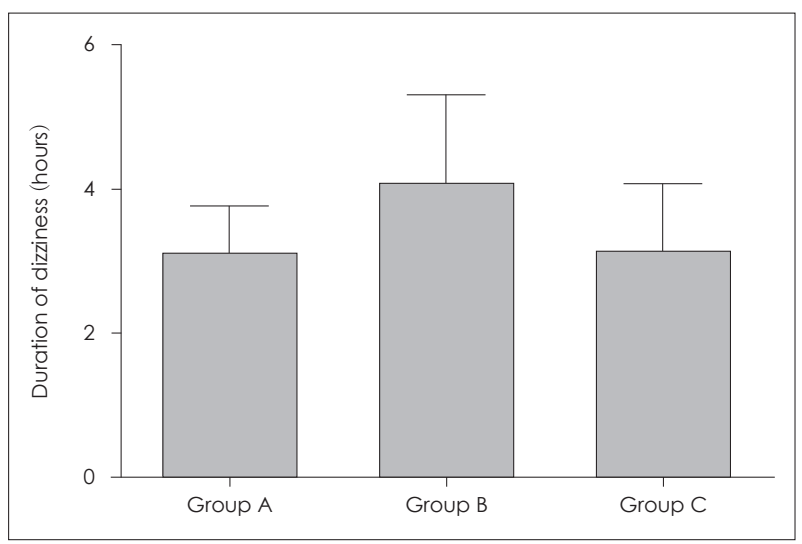

Fig. 2. Duration of dizziness in each group. There was no statistical difference among groups. Error bars indicate standard error $(p>0.05)$. Group A: low frequency fluctuation group (0.25, 0.5 $\mathrm{kHz})$, Group B: mid frequency flucutaion group (1, $2 \mathrm{kHz})$, and Group C: high frequency flucutaion group $(4,8 \mathrm{kHz})$.

어지럼증의 지속시간은 그룹 $\mathrm{A}$ 는 $3.0( \pm 4.2)$ 시간, 그룹 $\mathrm{B}$ 는 4.0( \pm 6.3$)$ 시간, 그룹 $\mathrm{C}$ 는 $3.9( \pm 4.7)$ 시간으로 통계적으로 유 의한 차이를 보이지 않았다(Kruskal-Wallis test, KW statistics=0.8456, $p=0.6552$ )(Fig. 2).

각 그룹 간 성별에 따른 청력 변동의 차이는 통계적으로 유의하지 않았으며(independent t-test, 그룹 $\mathrm{A}: p=0.117$; 그 룹 $\mathrm{B}: p=0.711$; 그룹 $\mathrm{C}: p=0.397)$ 환자의 평균 나이는 그룹 $\mathrm{A}$ 가 51.3( \pm 13.6$)$ 세, 그룹 B가 54.4( \pm 16.2$)$ 세, 그룹 C가 54.0( \pm 13.4)세로 그룹 $\mathrm{B}$ 와 그룹 $\mathrm{C}$ 가 그룹 $\mathrm{A}$ 에 비해 평균 연령이 높았 으나 통계적인 유의성은 없었다(one-way ANOVA, F=0.1820, $p=0.8339$ ). 청력 장애가 발생한 환측 부위와 두통 및 이충만 감의 동반 여부는 세 그룹 사이에 차이를 보이지 않았다.

이명이 동반된 환자의 수는 총 73명(85.9\%)이었다. 그룹 A 가 34명(94.4\%), 그룹 B가 22명(88.0\%), 그룹C가 17명(70.8\%) 
으로 그룹 $\mathrm{A}$ 의 경우가 이명의 동반 여부가 가장 높고 그룹 $\mathrm{C}$ 의 경우가 이명의 동반 여부가 가장 낮게 나타났으며 이명 동반 여부는 그룹들에서 통계적으로 유의한(Fisher's exact test: $p=0.042$ ) 차이를 보였다(Fig. 3).

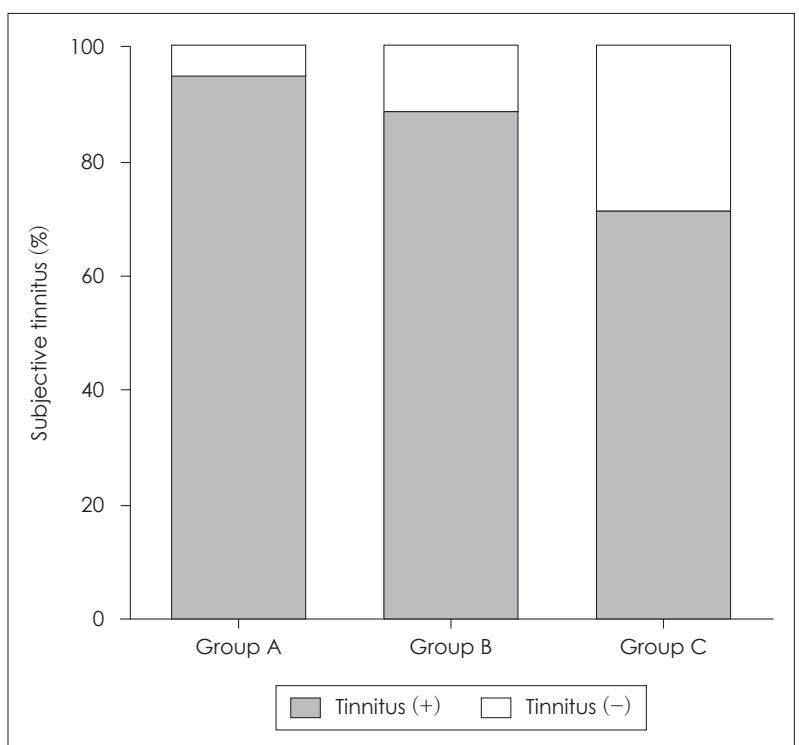

Fig. 3. Incidence of tinnitus in each group. Group A revealed highest incidence of tinnitus. Group B and Group C showed relatively less incidence compared to Group A. There was statistical difference in tinnitus incidence among groups (Fisher's exact test: $p<0.05)$. Group A: low frequency fluctuation group $(0.25,0.5 \mathrm{kHz})$, Group B: mid frequency flucutaion group $(1,2 \mathrm{kHz})$, and Group C: high frequency flucutaion group $(4,8 \mathrm{kHz})$.

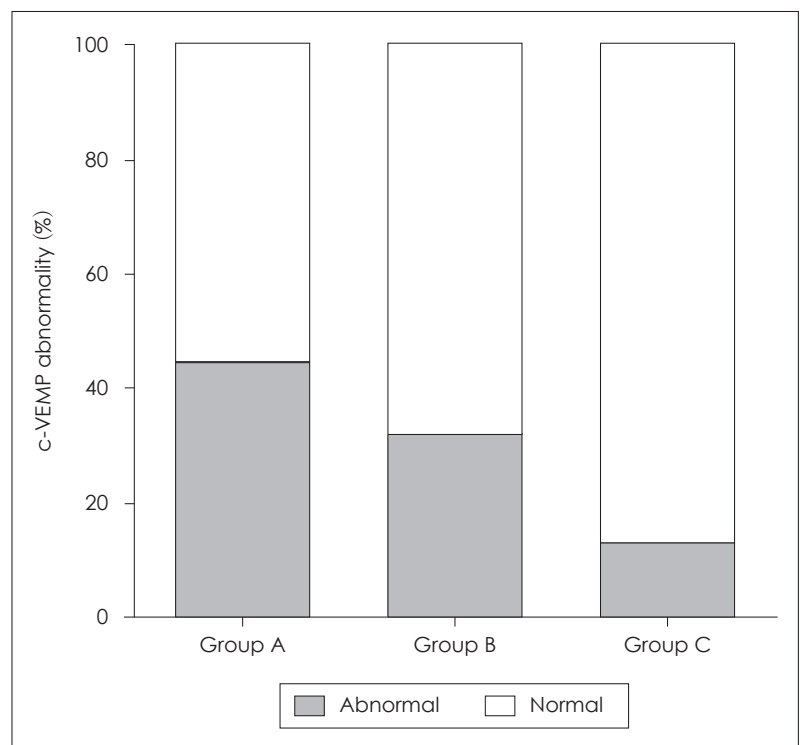

Fig. 4. Rate of c-VEMP abnormality. Group A revealed highest abnormal rate of c-VEMP. Group B and Group C showed relatively less incidence compared to Group A. There was statistical difference in VEMP abnormal rate among groups (Fisher's exact test: $p<0.05)$. Group A: low frequency fluctuation group $(0.25,0.5$ $\mathrm{kHz})$, Group B: mid frequency flucutaion group $(1,2 \mathrm{kHz})$, and Group C: high frequency flucutaion group $(4,8 \mathrm{kHz})$. VEMP: vestibular evoked myogenic potentials.
전기와우청력검사에서 이상 소견을 보이는 환자의 수는 그룹 $\mathrm{A}$ 가 32 명 중 17명(53.1\%), 그룹 B가 25명 중 11명(44.0\%), 그룹 C가 22명 중 14 명(63.6\%)이었다. 온도안진검사에서 이상 소견을 보이는 환자의 수는 그룹 A가 27명 중 11 명(40.7\%), 그룹 B가 18 명 중 6 명(33.3\%), 그룹 C가 18 명 중 10 명이었다 (55.6\%). 전기와우청력검사와 단일온도안진검사 모두 그룹 C 의 경우가 그룹 $\mathrm{A}$ 와 그룹 $\mathrm{B}$ 의 경우에 비해서 이상 소견을 보 이는 비율이 높았으나 통계적으로 유의하지 않았다(All; chisquared test: $p>0.05$ ).

전정유발근전위 검사에서 이상 소견을 보이는 환자의 수는 그룹 A가 34명 중 15명(44.1\%), 그룹 B가 22명 중 7명(31.8\%), 그룹 $\mathrm{C}$ 가 24명 중 3명(12.5\%)으로 그룹 $\mathrm{A}$ 로 갈수록 이상 소 견을 보이는 비율이 그룹 $\mathrm{C}$ 에 비하여 높았으며 전정유발근 전위의 이상 여부는 그룹 간에 통계적으로 유의한 차이를 보 였다(Fisher's exact test: $p=0.036$ )(Fig. 4).

\section{고 찰}

메니에르병은 흔히 감각신경성 난청과 연관이 있으며 대부 분의 경우 청력검사에서 저주파수 영역의 청력장애로 나타난 다고 알려져 있다. 이번 연구에서는 명확한 메니에르병 환자 를 대상으로 하였을 때 저주파수 영역뿐만 아니라 중간 및 고주파수 영역의 청력 변동이 있는지 확인하고 이를 통해서 가청 주파수 전 영역에 걸쳐서 청력 변동이 동반되는지 확인 하고자 하였으며, 그 결과 명확한 메니에르병 환자의 경우 청 력장애 발생 시 저주파수 영역의 청력 변동(42.0\%)뿐만 아니 라 중간주파수(30.0\%) 및 고주파수(28.0\%) 영역의 청력 변동 도 발생할 수 있음을 확인하였다. 모든 주파수 영역의 청력 변동이 존재한다는 것은 메니에르병의 진행 과정상 와우의 전 영역에 걸쳐서 질환이 영향을 미친다는 것을 시사하고 있다.

메니에르병에서 이명은 청력장애 및 어지러움증과 마찬가 지로 내이림프수종과 같은 상태이상으로 기인한다. ${ }^{4)}$ 내이림 프수종의 기전은 내이림프공간의 확장에 의해 야기된다. 내 림프액의 과생산 및 흡수 장애는 내이 세포를 손상시켜서 미 로의 압력을 증가시키고 미로 막 파열 및 코르티 기관의 칼 륨 독성을 야기한다. ${ }^{9,10)}$ 이번 연구에 포함된 명확한 메니에르 병 환자 85명 중 73명이 이명을 호소하고 있으며(85.9\%) 각 주 파수 군별로 비교하였을 때 저주파수가 34명(94.4\%), 중간주 파수가 22명(88.0\%), 고주파수가 17명(70.8\%) 이었다. 성인 대 상으로 한 조사에서 $32 \%$ 가 이명을 호소하고 있는 것에 비하 여 ${ }^{11)}$ 명확한 메니에르병 환자의 경우 이명의 동반 비율이 정상 성인에 비하여 높으며, 특히 명확한 메니에르병 환자 중에서 도 저주파수 영역의 청력 변동이 있는 환자들의 경우 중간 
및 고주파수 영역의 청력 변동이 있는 환자보다 이명의 동반 비율이 높은 것을 확인했다. 이 결과는 주관적 이명이 고주파 에서 더 흔하다는 점 ${ }^{12)}$ 을 생각하면 의외의 결과이다. 이 결과 의 원인으로는 몇 가지를 생각해 볼 수 있다. 첫째, 환자들에 게는 이충만감도 이명에 해당하며 그 빈도가 높게 측정되었 을 가능성이 있다. 둘째로는 고주파 영역의 이명의 발생은 다 른 주관적 이명과 같이 난청 이후에 시간이 지난 후에 발생하 는 경우가 많기 때문에 ${ }^{13)}$ 조사 당시의 난청 발생 초기에는 그 빈도가 적었을 가능성이 있다. 보다 정확한 분석을 위해서는 이명도 검사의 분석을 통한 연구가 필요할 것으로 생각된다.

내이림프수종을 반영하는 검사로 이용되는 전기와우도검 사는 메니에르병의 병태 생리를 반영하는 유용한 검사 방법 이지만 환자가 호소하는 증상에 따라서 결과의 차이가 발생 하고 어느 정도 청력 소실이 있는 경우에는 파형이 나타나지 않 아 임상적으로 적용되기 어렵다. ${ }^{14)}$ 경부 전정유발근전위검사 는 구형낭의 기능을 반영하는 검사 방법으로 양이간 진폭차 (IAD)가 메니에르병의 병기와 관련되어 있는 것은 이미 알려 진 사실이다. ${ }^{15,16)}$ 메니에르병 환자의 사후 측두골을 이용한 연구에서(총 22예) 관찰 소견으로 구형낭에서는 모든 경우에 서 내림프수종이 관찰되었다. 이외에도 와우(19예), 난형낭 (11예), 반고리관(5예)에서 내림프수종이 관찰되었다. ${ }^{17)}$ 이를 통해서 구형낭의 기능을 반영하는 전정유발근전위검사를 시 행함으로써 메니에르병의 진단과 예후에 유용한 정보를 줄 수 있다.

이번 연구에 포함된 명확한 메니에르병 환자 85 명 중 80 명 에서 전정유발근전위검사를 시행하였고 80 명의 환자 중에서 25명의 환자에서 이상 소견을 보였고(31.3\%) 각 주파수 군별 로 이상 소견을 보이는 환자의 비율을 확인했을 때 저주파수 가 15명(44.1\%), 중간주파수가 7명(31.8\%), 고주파수가 3명 (12.5\%)이었다. 전정유발근전위검사에서 이상 소견을 보이는 경우는 주파수 군별로 다양하게 나타났지만 저주파수 영역 의 청력 변동이 있는 환자의 경우 전정유발근전위검사에서 이 상 소견을 보이는 경우가 더 많은 것을 알 수 있었고 이는 통 계적으로 유의한 것을 확인하였다. 메니에르병에서 vestibular evoked myogenic potentials(VEMP)결과의 이상 소견이 돌 발성 난청에 비해 더 흔히 발생한다는 보고가 있다. Young 등 ${ }^{15)}$ 은 저주파수 영역의 청력 감소가 흔한 메니에르병은 VEMP 소실과 관련이 있다고 하였으며 고주파수 영역에서 청력 감 소를 주로 보인 돌발성 난청 환자는 정상적인 VEMP 파형을 보였다고 보고하였다. 하지만 고주파 청력 변동이 심한 메니 에르병 환자에서 VEMP의 이상 소견이 적다는 보고는 본 연 구가 최초이다. 이 결과의 해석은 현재로서는 매우 힘드나 한 편으로는 이를 통해 고주파 청력 변동과 저주파수 청력 변동
의 원인이 다를 가능성을 추측해 볼 수 있다. 저주파수 청력 의 변동은 내이림프수종에서 비롯할 것으로 추측되고, 이러 한 내이림프수종의 정도에 따라 와우에 가까운 saccule의 기 능을 대변하는 VEMP 결과의 이상 소견이 발생하는 것은 가능할 법하다. ${ }^{16}$ 한편 고주파 영역의 변동은 다른 이유로 발 생할 가능성이 있다. 그 근거가 되는 점은 $\mathrm{VEMP}$ 의 이상 소 견을 동반하지 않았고 청력 변동의 특징(호전/악화)을 확인 해보면, 고주파에서 가장 흔한 변화 양상은 악화 이후 호전 이라는 점이다. 고주파수 영역의 와우(기저부)는 첨부나 전정 기관에 비해 여러 자극에 약하다는 사실은 이미 잘 알려져 있고 ${ }^{18)}$ 이를 적용해 보면 고주파수의 청각 변화는 소음성 난 청에서의 transient threshold shift와 같은 일시적인 기저부 유모세포의 기능 저하에 의한 것으로 추측해 볼 수 있다. 하 지만 이 결과를 해석할 때에는 본 연구에서 IAD ratio가 병변 측이 감소되어 있는 것이 VEMP의 이상 소견으로 한정 지은 점을 고려해야 한다. 추가적으로 VEMP threshold 혹은 characteristic frequency의 변화 등의 연구가 필요하다.

본 연구에서 디자인 및 결과에서 부족한 점이 여러 가지 있 다. 우선 이명을 호소하는 73명의 환자 중에서 이명도 검사 (tinnitogram)를 시행한 환자는 총 10명밖에 되지 않았다, 그 중에서 순음청력검사의 청력 변동과 일치하는 환자는 3 명이 었다. 또한, 이명을 호소하는 73명의 환자 중에서 7명의 환자 에서만 이명장애지수 설문지(Tinnitus handicap index)를 시 행하였다. 앞으로 이명을 호소하는 메니에르병 환자의 경우 순음청력검사뿐만 아니라 이명도 검사와 이명장애지수 설문 지를 동시에 시행하여 메니에르병 환자에서 이명의 강도와의 관련성과 이명이 일상생활에 미치는 영향과 같은 연구가 시 행되어야 할 것이다. 양온 교대 온도 안진 검사가 아닌 단일 온 도 안진 검사 만이 사용되었다는 점도 역시 한계점이다. 물론 메니에르병에서 칼로릭 검사의 결과가 다양하게 보고되고 있 지만 ${ }^{19,20)}$ 추가적인 연구에서는 양온 교대 온도 안진 검사 결과 와 청력 변화 양상의 분석이 필요할 것이다.

그리고 이번 연구에 포함된 명확한 메니에르병 환자의 진단 이 기존에 해당하던 1995년 American Academy of Otolaryngology-Head and Neck Surgery의 기준으로 한 점이 한계 가 있을 것으로 보여 향후에는 저-중주파수 감각신경성 청력 저하 환자들을 메니에르병으로 정의 내린 새로운 진단 기준 (2015년 International criteria)을 통한 명확한 메니에르병 환 자의 선정과 이에 따른 임상 양상과 전정기능검사의 관련 유 무를 비교 분석해야 할 것이다.

\section{REFERENCES}

1) Schuknecht HF. Disorders of bone. Pathology of the Ear. Philadelphia: 
Lea \& Fcbiger; 1993.

2) Stahle J, Stahle $C$, Arenberg IK. Incidence of Ménière's disease. Arch Otolaryngol 1978;104(2):99-102.

3) Savastano M, Guerrieri V, Marioni G. Evolution of audiometric pattern in Meniere's disease: long-term survey of 380 cases evaluated according to the 1995 guidelines of the American Academy of Otolaryngology-Head and Neck Surgery. J Otolaryngol 2006;35(1): 26-9.

4) Stahle J, Friberg U, Svedberg A. Long-term progression of Menière's disease. Am J Otol 1989;10(3):170-3.

5) Takumida M, Kakigi A, Takeda T, Anniko M. Ménière's disease: a long-term follow-up study of bilateral hearing levels. Acta Otolaryngol 2006;126(9):921-5.

6) McNeill C, Cohen MA, Gibson WP. Changes in audiometric thresholds before, during and after attacks of vertigo associated with Meniere's syndrome. Acta Otolaryngol 2009;129(12):1404-7.

7) Hoa M, Friedman RA, Fisher LM, Derebery MJ. Prognostic implications of and audiometric evidence for hearing fluctuation in Meniere's disease. Laryngoscope 2015;125 Suppl 12:S1-12.

8) Committee on Hearing and Equilibrium. Committee on Hearing and Equilibrium guidelines for the diagnosis and evaluation of therapy in Menière's disease. American Academy of Otolaryngology-Head and Neck Foundation, Inc. Otolaryngol Head Neck Surg 1995;113 (3):181-5.

9) Schuknecht HF. Meniere's disease: a correlation of symptomatology and pathology. Laryngoscope 1963;73(6):651-65.

10) Dohlmann GF. On the mechanism of the Menière attack. Arch Otorhinolaryngol 1976;212(4):301-7.

11) Bailey BJ. Head and neck surgery: otolaryngology. Philadelphia: Lippincott Williams \& Wilkins;1998.

12) Kim DK, Park SN, Kim HM, Son HR, Kim NG, Park KH, et al.
Prevalence and significance of high-frequency hearing loss in subjectively normal-hearing patients with tinnitus. Ann Otol Rhinol Laryngol 2011;120(8):523-8.

13) Schaette R, Kempter R. Development of tinnitus-related neuronal hyperactivity through homeostatic plasticity after hearing loss: a computational model. Eur J Neurosci 2006;23(11):3124-38.

14) Gibson WP. A comparison of two methods of using transtympanic electrocochleography for the diagnosis of Meniere's disease: click summating potential/action potential ratio measurements and tone burst summating potential measurements. Acta Otolaryngol Suppl 2009;560:38-42.

15) Young $\mathrm{YH}, \mathrm{Wu} \mathrm{CC}, \mathrm{Wu} \mathrm{CH}$. Augmentation of vestibular evoked myogenic potentials: an indication for distended saccular hydrops. Laryngoscope 2002;112(3):509-12.

16) Young YH, Huang TW, Cheng PW. Assessing the stage of Meniere's disease using vestibular evoked myogenic potentials. Arch Otolaryngol Head Neck Surg 2003;129(8):815-8.

17) Welgampola MS, Colebatch JG. Characteristics and clinical applications of vestibular-evoked myogenic potentials. Neurology 2005;64(10): 1682-8.

18) Cronin S, Lin A, Thompson K, Hoenerhoff M, Duncan RK. Hearing loss and otopathology following systemic and intracerebroventricular delivery of 2-hydroxypropyl-beta-cyclodextrin. J Assoc Res Otolaryngol 2015;16(5):599-611.

19) McGarvie LA, Curthoys IS, MacDougall HG, Halmagyi GM. What does the head impulse test versus caloric dissociation reveal about vestibular dysfunction in Ménière's disease? Ann N Y Acad Sci 2015;1343:58-62.

20) Sharon JD, Hullar TE. Motion sensitivity and caloric responsiveness in vestibular migraine and Meniere's disease. Laryngoscope 2014; 124(4):969-73. 